\title{
Oligo- and Poly-thiophene/ZnO Hybrid Nanowire Solar Cells
}

\author{
Alejandro L. Briseno, Thomas W. Holcombe, Akram I. Boukai, Erik C. Garnett, Steve \\ W. Shelton, Jean J. M. Fréchet*, Peidong Yang* \\ Department of Chemistry, University of California, Berkeley, California 94720, and \\ Materials Sciences Division, Lawrence Berkeley National Laboratory, Berkeley, \\ California 94720
}

RECEIVED DATE;

Email: p_yang@berkeley.edu; frechet@berkeley.edu

\begin{abstract}
We demonstrate the basic operation of an organic/inorganic hybrid single nanowire solar cell. End-functionalized oligo- and poly-thiophenes were grafted onto $\mathrm{ZnO}$ nanowires to produce $\mathrm{p}-\mathrm{n}$ heterojunction nanowires. The hybrid nanostructures were characterized via absorption and electron microscopy to determine the optoelectronic properties and to probe the morphology at the organic/inorganic interface. Individual nanowire solar cell devices exhibited well-resolved characteristics with efficiencies as high as $0.036 \%$, Jsc $=$ $0.32 \mathrm{~mA} / \mathrm{cm}^{2}, \mathrm{Voc}=0.4 \mathrm{~V}$, and a FF= 0.28 under AM 1.5 illumination with $100 \mathrm{~mW} / \mathrm{cm}^{2}$ light intensity. These individual test structures will enable detailed analysis to be carried out in areas that have been difficult to study in bulk heterojunction devices.
\end{abstract}


Hybrid solar cells composed of organic semiconductors ${ }^{1}$ and inorganic nanostructures ${ }^{2}$ are an area of immense study as they are alternatives to organic bilayer ${ }^{3}$ and bulk heterojunction device structures. ${ }^{4,5}$ The organic/inorganic hybrid system ${ }^{6-9}$ has opened new opportunities for the development of future generation solar cells, new device technologies, and a platform to study three-dimensional morphology. ${ }^{10} \mathrm{~A}$ multitude of concepts have been demonstrated by combining p-type donor polymers with n-type acceptor inorganic nanostructures such as $\mathrm{CdSe},{ }^{6,7,11} \mathrm{TiO}_{2},{ }^{8-10,12-15}$ and $\mathrm{ZnO} .{ }^{8-10,14}$ One-dimensional (1-D) inorganic semiconductor nanostructures are among some of the most attractive nanomaterials for solar cell devices because they provide a direct path for charge transport. $^{2}$ Other advantages include high carrier mobilities, solution processability, thermal and ambient stability, and a high electron affinity necessary for charge injection from the complementary organic donor material. $\mathrm{ZnO}$ nanowires are an example of this class of materials that have been used for hybrid solar cells. ${ }^{8-10,14,16}$ Poly(3-hexylthiophene) (P3HT)/ZnO nanowire composite solar cells are benchmark systems that have attained power conversion efficiencies ranging from 0.02 to $2 \% .{ }^{9,16,17}$ In spite of the vast efforts in this area of research, solar cells based on hybrid composites have yielded efficiencies only close to those of organic bilayer devices and significantly less than organic bulk heterojunction solar cells. Knowledge regarding interfacial charge separation and/or transport in hybrid nanowire devices is only partly understood. ${ }^{10,17}$ If this class of materials is to play a part in the future of next generation solar cells, then there must be an improved fundamental understanding of the organic/inorganic interface in order to improve power conversion efficiencies. While nanowire array and bulk inorganic/organic blend devices are technologically relevant, their electrical properties 
depend on nanostructure size, uniformity, crystallinity, phase segregation, interfacial interactions, mobility, trap density and many other factors. For macroscopic devices, these parameters can vary significantly over the active area, making it difficult to attribute any change in performance to a particular phenomenon. Single nanowire devices allow for more precise control over and characterization of the properties listed above, greatly reducing the uncertainty in data interpretation.

In this study, we utilize end-functionalized p-type oligo- and poly-thiophene to chemically graft the organic component to an $\mathrm{n}$-type $\mathrm{ZnO}$ nanowire, producing a $\mathrm{p}-\mathrm{n}$ core-shell nanowire from which we subsequently fabricated a single nanowire solar cell. We end-functionalized P3HT and quaterthiophene with a phosphonic ester and acid, respectively, and self-assembled the semiconductors onto the $\mathrm{ZnO}$ surface in the solution phase to yield organic shells with thicknesses of about 5-20 nm. We present results on the synthesis and characterization of the organic/ZnO composites, high-resolution transmission electron microscopy (TEM) of the organic/ZnO interface, as well as results on the photovoltaic characteristics of individual nanowire devices. The nanowire devices yield low efficiencies of about $0.03 \%$, but provide an effective platform for isolating and studying the many phenomena that affect bulk hybrid solar cell performance.

$\mathrm{ZnO}$ nanowires were prepared via solution and vapor-phase synthesis as previously reported. ${ }^{18-20}$ Both methods can produce high-quality, single crystalline nanowires with lengths of several microns and diameters ranging from 30-100 nm. Regioregular P3HT was prepared from 2-bromo-3-hexyl-5-iodo thiophene through the Grignard metathesis (GRIM) reaction ${ }^{21}$ to afford a bromine-terminated polymer with a molecular weight of $\sim 7000 \mathrm{Da}$ as determined via MALDI-TOF. End-functionalization was carried out by 
reacting P3HT-Br with butyllithium and then diethylchlorophosphate to yield a phosphonic ester. Didodecylquaterthiophene (QT) was end-functionalized via a similar pathway, however, the ester was subsequently hydrolyzed to afford a phosphonic acid. We note that the P3HT-phosphonic ester was not hydrolyzed to the phosphonic acid since the reaction conditions using trimethylsilyl bromide degrade the properties of P3HT. Figure 1 shows the synthetic steps towards functionalization of the two organic materials. Details of the synthesis and characterization are included in the supporting information. We obtained core-shell nanowires by stirring a suspension of $\mathrm{ZnO}$ nanowires in a 2 $\mathrm{mg} / \mathrm{ml}$ chlorobenzene solution of the respective functionalized organic components overnight. The composite materials were purified by centrifugation followed by removal of the supernatant containing excess organic component. THF was added to the precipitated nanowires and the purification step was repeated an additional three times. No efforts were made to vary the concentration of the oligothiophene in organic solvent. However, we did substitute THF and chloroform for chlorobenzene, and similar results were obtained. Large-scale quantities $(\sim 20 \mathrm{mg})$ of functionalized nanowires were prepared from both organic components. Dry powders were stored in a nitrogen box to prevent oxidation. $\mathrm{ZnO} / \mathrm{P} 3 \mathrm{HT}$ composites are light purple in color while the $\mathrm{ZnO} / \mathrm{QT}$ composites are yellow (Figure 2). The hybrid nanowires can be easily re-dispersed by sonicating in methanol for 5-10 seconds.

We verified the grafting of oligothiophenes onto $\mathrm{ZnO}$ nanowires via $\mathrm{UV}$ absorption spectroscopy. Arrays of $\mathrm{ZnO}$ nanowires on quartz substrates were employed in this experiment because light scattering prevented solutions of the hybrid nanowires from yielding quality spectra. Grafting of the organic component onto $\mathrm{ZnO}$ arrays were carried 
out under similar conditions as described for solution-phase nanowires. Figure 2 shows the schematic structure of the hybrid $\mathrm{ZnO}$ nanowire arrays and the solid state absorption spectra of $\mathrm{ZnO} / \mathrm{P} 3 \mathrm{HT}$ and $\mathrm{ZnO} / \mathrm{QT}$. Figure $2 \mathrm{C}$ shows an overlay of the pristine endfunctionalized P3HT spin-coated on a quartz substrate and the P3HT-modified $\mathrm{ZnO}$ nanowires. The peak centered at $\sim 370 \mathrm{~nm}$ corresponds to the $\mathrm{ZnO}$ absorption, while the three low energy bands are attributed to the vibronic transitions of P3HT. Figure 2D shows the spectra of the pristine phosphonic acid-terminated quaterthiophene and an overlay of the $\mathrm{ZnO} / \mathrm{QT}$ nanowire array. The $\mathrm{ZnO}$ absorption is again observed at $\sim 370$ $\mathrm{nm}$ while a broad shoulder centered at $\sim 400 \mathrm{~nm}$ correlates well with the absorption band of the free QT oligomer.

High-resolution TEM was used to determine the thickness of the grafted organic components onto $\mathrm{ZnO}$ nanowires. Figures 3A-3C show TEM micrographs of $\mathrm{ZnO} / \mathrm{P} 3 \mathrm{HT}$ hybrid structures with P3HT thicknesses ranging from about $7-20 \mathrm{~nm}$. The grafting of P3HT onto $\mathrm{ZnO}$ results in a somewhat uneven morphology, yet, complete coverage throughout the surface of the nanowires is reproducibly observed. Figures 3D-3F show TEM micrographs of $\mathrm{ZnO} / \mathrm{QT}$ hybrid nanowires with shell thicknesses ranging from 6 $13 \mathrm{~nm}$. It is worth pointing out that small-molecule grafting shows significantly smoother shells compared to P3HT grafts. The reason is unclear, but it may be possible that nanoscale disorder predominates in self-assembled polymer thin films compared to smallmolecule thin films. This does not imply that P3HT is unable to self-assemble into highly ordered domains. In fact, we repeatedly observed highly organized domains when $\mathrm{ZnO} / \mathrm{P} 3 \mathrm{HT}$ nanowires were imaged with HR-TEM as shown in Figure 3C. This organization is known as lamellar chain packing and is documented in literature for thin 
films of P3HT. ${ }^{22}$ Brinkman and coworkers observed lamellar organization with P3HT thin films using HR-TEM bearing similar molecular weights to that of our P3HT. ${ }^{23}$ From the known unit cell parameters of $\mathrm{P} 3 \mathrm{HT},{ }^{22,23}$ the averaged molecular weight, and the chemical repeat unit of $\mathrm{P} 3 \mathrm{HT}$, one could estimate the length of a $\mathrm{P} 3 \mathrm{HT}$ chain and explain the shell thickness based on the lamellar repeat folding (along c-axis of chain). For instance, the estimated unit cell parameters for P3HT from literature are, $a=16.2 \AA, b=$ 3.8 $\AA$, and $c=7.8 \AA,{ }^{21-23}$ and from an $\sim 7 \mathrm{kDa}$ polymer determined from MALDI-TOF, a shell thickness of about $6-11 \mathrm{~nm}$ is estimated. This is assuming the lamellar fold length is on the order of $5-10 \mathrm{~nm}$ based on our TEM images (Figure 3C) and from measurements in literature reports. ${ }^{22,23}$ A diagrammatic illustration of the chain packing at the $\mathrm{ZnO}$ interface as shown in Figure 4A. We note that this illustration is not to scale and the intent is to show a plausible scheme of lamellar chain packing on the surface of $\mathrm{ZnO}$.

The molecular packing of QT on $\mathrm{ZnO}$ is highly uniform, as evidenced by the smooth shell on $\mathrm{ZnO}$ from Figure 3E. The length of a QT molecule is about $1.9 \mathrm{~nm}$, however, shell thicknesses of 6-13 $\mathrm{nm}$ are measured by TEM. This can be explained by the QT bilayers which are strongly interacting via three molecular forces. A schematic illustration of the proposed solid-state structure is shown in Figure 4B. The planar backbone of QT forms $\pi-\pi$ interactions with next-nearest neighbor molecules along the plane of the $\mathrm{ZnO}$ nanowire. H-bonding between end-functionalized phosphonic acid groups from QT bilayers also interact strongly with one another to stabilize the molecular framework. Phosphonic acids are capable of forming strong $\mathrm{P}-\mathrm{O}-\mathrm{H} \cdots \mathrm{O}=\mathrm{P}$ hydrogen interactions with a bond strength of approximately $10-20 \mathrm{kcal} / \mathrm{mol} .{ }^{24} \mathrm{Jen}$ and coworkers 
previously reported similar interactions with pyrene phosphonic acid molecules that form polycrystalline films through $\pi$-interactions and $\mathrm{H}$-bonding. ${ }^{25}$ In addition to the two forces that we discussed, QT frameworks are also assisted by van der Waals interactions between dodecyl side-chains. Therefore, if three bilayers of QT stack vertically, a thickness of about $9 \mathrm{~nm}$ can be estimated. Well-ordered architectures composed of alternating oligothiophene/ZnO lamellar nanostructures were recently reported by Stupp and coworkers. ${ }^{26}$ In their study, the hybrid nanocomposite was employed as a photoconductor device that generated extremely large spectral responsivities. It has also been shown that end-functionalized oligothiophenes can self-assemble onto $\mathrm{ZnO}$ nanorods as highly crystalline monolayers. ${ }^{27}$ The molecules were found to pack in a herringbone pattern and the packing density correlated well with a core-shell thickness of $\sim 3 \mathrm{~nm}$. The hybrid nanostructures were subsequently fabricated into transistors and ambipolar behavior was observed. ${ }^{27}$

The p-n heterojunction nanowires were further characterized by measuring their photovoltaic characteristics. The organic/ZnO nanowires were dispersed in methanol and drop cast onto oxidized silicon substrates. The nanowire devices were fabricated by a top contact approach using electron beam lithography (EBL). Part of the organic shells were etched away from $\mathrm{ZnO}$ nanowires using oxygen plasma through defined EBL patterns. Next we deposited aluminum electrodes $(100 \mathrm{~nm})$ to make ohmic contacts directly onto ZnO. EBL was utilized again to define and deposit gold electrodes $(100 \mathrm{~nm})$ directly onto oligothiophene shells. Figure 5A shows a schematic configuration of a completed nanowire device. All photovoltaic measurements were carried out in a vacuum probe station $\left(10^{-6}\right.$ Torr) equipped with a solar simulator (Oriel). Figure $5 \mathrm{~B}$ and $5 \mathrm{C}$ show 
current-voltage (I-V) characteristics for the two types of photovoltaic cells investigated for this work. The plot of a typical $\mathrm{ZnO} / \mathrm{P} 3 \mathrm{HT}$ nanowire device yielded a $\mathrm{J}_{\mathrm{SC}}$ of $\sim 0.32$ $\mathrm{mA} / \mathrm{cm}^{2}, \mathrm{~V}_{\mathrm{OC}}$ of $\sim 0.40 \mathrm{~V}$, FF of $\sim 0.28$, and an efficiency of $\sim 0.036 \%$ under AM 1.5 illumination with $100 \mathrm{~mW} / \mathrm{cm}^{2}$ light intensity (Figure 5B). These results are consistent with literature values of $\mathrm{ZnO} / \mathrm{P} 3 \mathrm{HT}$ bulk nanowire solar cells where the average characteristics yielded a $\mathrm{Jsc}$ of $0.74 \mathrm{~mA} / \mathrm{cm}^{2}, \mathrm{~V}_{\mathrm{OC}}$ of $0.17 \mathrm{~V}, \mathrm{FF}$ of 0.34 , and an efficiency of $0.04 \% .{ }^{9}$ This suggests that increasing the P3HT thickness will not significantly improve the performance of the nanowire device (assuming the exciton diffusion length of P3HT is similar or less than the core-shell thickness of $10 \mathrm{~nm}$ ). Since P3HT defines the optical absorption in our nanowire device, we calculated the maximum current density by integrating the absorption coefficient of end-functionalized P3HT over the solar spectrum (AM 1.5) ${ }^{28}$ and estimated a current density of $\sim 0.75 \mathrm{~mA} / \mathrm{cm}^{2}$. This difference in experimental versus theoretical current density is similar to that in bulk heterojunction solar cells where a maximum current is calculated at $\sim 19 \mathrm{~mA} / \mathrm{cm}^{2}$ and experimental results yield about $10-12 \mathrm{~mA} / \mathrm{cm}^{2} .{ }^{28}$

Similar photovoltaic results were found for a $\mathrm{ZnO} / \mathrm{QT}$ nanowire device (Figure 5C) yielding a Jsc of $0.29 \mathrm{~mA} / \mathrm{cm}^{2}, \mathrm{~V}_{\mathrm{OC}}$ of $0.35 \mathrm{~V}$, FF of 0.32 , and an efficiency of $0.033 \%$. The important finding in this work is that the open circuit voltage in our devices are larger than those reported in literature ${ }^{9,29}$ from $\mathrm{ZnO} / \mathrm{P} 3 \mathrm{HT}$ bulk nanowire array devices. This may suggest that the $\mathrm{ZnO} / \mathrm{P} 3 \mathrm{HT}$ interface for the grafted polymer is superior to the bulk spin-coated method. It is also possible that single-nanowire devices increase the shunt resistance by eliminating shorting paths present in the bulk $\mathrm{ZnO}$ array devices. There remains significant room for improvement of these devices by modifying the 
device fabrication procedure and electrode deposition technique. Nevertheless, ideal characteristics and reproducible measurements were observed in these devices. Although one could argue that device performance will be limited by the thickness of the grafted oligothiophene (since more material will absorb more sunlight), the reality is that only the excitons that are photogenerated within a diffusion length of the respective material will be effectively dissociated at the interface, transported, and collected into the external circuit. Smaller band gap semiconductor nanowires and organic semiconductors with larger absorption coefficients, longer diffusion lengths, and higher mobilities will be best suited for improving the performance in single nanowire devices. These devices will play a critical role in understanding fundamental device physics at interfaces and in the development of new device concepts and technologies.

In summary, we demonstrated basic operation of individual organic/inorganic hybrid nanowire solar cells. End-functionalized oligo- and poly-thiophenes were grafted onto $\mathrm{ZnO}$ nanowires to produce $\mathrm{p}-\mathrm{n}$ heterojunction nanowires. The hybrid nanostructures were characterized via absorption and electron microscopy to determine the optoelectronic properties and to probe the morphology at the organic/inorganic interface. Hybrid p-n heterojunction nanowire solar cell devices exhibited ideal characteristics. These individual test structures will enable detailed analysis to be carried out in areas that have been difficult to study in nanostructured array and heterojunction devices.

Acknowledgments. This work was supported by the Director, Office of Science, Office of Basic Energy Sciences, Materials Sciences and Engineering Division, of the U.S. Department of Energy under Contract No. DE-AC02-05CH11231. TWH thanks the NSF 
for a graduate research fellowship. The authors thank Yunjeong Hwang for assistance with SEM measurements, Michael Moore and Michelle N. Comte for the preparation of $\mathrm{ZnO}$ nanowires, and Ruoxue Yan for the schematic drawings in Figure $2 \& 5$.

\section{References.}

[1] Heremans, P.; Cheyns, D.; Rand, B. P., Acc. Chem. Res. 2009, ASAP DOI: 10.1021/ar9000923

[2] Xia, Y.; Yang, P.; Sun, Y.; Wu, Y.; Mayers, B.; B. Gates, B.; Yin, Y.; Kim, F.; Yan, H., Adv. Mater. 2003, 15, 353.

[3] Peumans, P.; Uchida, S.; Forrest, S. R., Nature 2003, 425, 158-162.

[4] Yu, G.; Gao, J.; Hummelen, J. C.; Wudl, F.; Heeger, A. J., Science 1995, 270, 1789-1791.

[5] Thompson, B.C.; Frechet, J. M. J., Angew. Chem. 2008, 47, 58-77.

[6] Huynh, W. U.; Dittmer, J. J.; Alivisatos, A. P., Science 2002, 295, 2425-2427.

[7] Liu, J. S.; Tanaka, T.; Sivula, K.; Alivisatos, A. P.; Frechet, J. M. J., J. Am. Chem. Soc. 2004, 126, 6550-6551.

[8] M. Law, L. E. Greene, J. C. Johnson, R. Saykally, P. Yang, Nat. Mater. 2005, 4, 455459.

[9] L. Greene, M. Law, B. Yuhas, P. Yang, J. Phys. Chem. C. 2007, 111, 18451-18456.

[10] Oosterhout, S. D.; Wienk, M. M.; van Bavel, S. S.; Thiedmann, R.; Koster, L. J. A.; Gilot, J.; Loos, J.; Schmidt, V.; Janssen, R. A. J., Nat. Mater. 2009, 8, 818-824.

[11] Sun, B. Q.; Marx, E.; Greenham, N. C., Nano Lett. 2003, 3, 961-963.

[12] Arango, A. C.; Carter, S. A.; Brock, P. J., Appl. Phys. Lett. 1999, 74, 1698-1700.

[13] Coakley, K. M.; McGehee, M. D., Appl. Phys. Lett. 2003, 83, 3380-3382.

[14] Law, M.; Greene, L. E.; Radenovic, A.; Kuykendall, T.; Liphardt, J.; Yang P., J. Phys. Chem. B 2006, 110, 22652-22663.

[15] Oomman K.; Varghese, M. P.; Grimes, C. A., Nat. Nanotech. 2009, 4, 592-597.

[16] Olson, D. C., Shaheen, S. E., Collins, R. T. \& Ginley, D. S., J. Phys. Chem. C 2007, $111,16640-16645$

[17] Lin, Y. Y.; Lee, Y. Y.; Chang, L.; Wu, J. J.; Chen C. W. Appl. Phys. Lett. 2009, 94, 063308.

[18] Greene, L.; Yuhas, B.; Law, M.; Yang, P., Inorg. Chem. 2006, 45, 7535-7543.

[19] Greene, L.; Law, M.; Goldberger, J.; Kim, F.; Johnson, J.; Zhang, Y.; Saykally, R.; Yang, P., Angew. Chem. 2003, 42, 3031-3034.

[20] M. Huang, Y. Wu, H. Feick, N. Tran,E. Weber, P. Yang, Adv. Mater. 2001, 13(2), $113-117$.

[21] Osaka, I.; McCullough R. D., Acc. Chem. Res. 2008, 41, 1202-1214.

[22] Mena-Osteriz, E.; Meyer, A.; Langeveld-Voss, B. M. W.; Janssen, R. A. J.; Meijer, E.W.; Bäuerle, P., Angew. Chem. 2000, 39, 2679-2684.

[23] Brinkmann, M.; Wittmann, J. C., Adv. Mater. 2006, 18, 860-863.

[24] Noldeb, C.; Schürmannb, M.; Mehringm M., Z. Anorg. Allg. Chem. 2007, 633, 142150. 
[25] Yip, H. L.; Ma, H.; Jen, A. K. Y; Dong, J.; Parviz, B. A., J. Am. Chem. Soc. 2006, $128,5672-5679$.

[26] (a) Sofos, M.; Goldberger, J.; Stone, D. A.; Allen, J. E.; Ma, Q.; Herman, D. J.; Tsai, W. W.; Lauhon, L. J.; Stupp, S. I., Nat. Mater. 2009, 8, 68-75 (b) Briseno, A. L.; Yang, P., Nat. Mater., 2009, 8, 7.

[27] Martini, C.; Poize, G.; Ferry, D.; Kanehira, D.; Yoshimoto, N,l Ackermann, J.; Fages, F., Chem. Phys. Chem. 2009, 10, 2465-2470.

[28] Dennler, G.; Scharber, M.C.; Brabec, C. J. Adv. Mater. 2009, 21, 1323-1338.

[29] Lin, Y-Y.; Lee, Y-Y.; Chang, L.; Wu, J-J. ; Chen, C-W. Appl. Phys. Lett. 2009, 94, 063308-1. 
A)

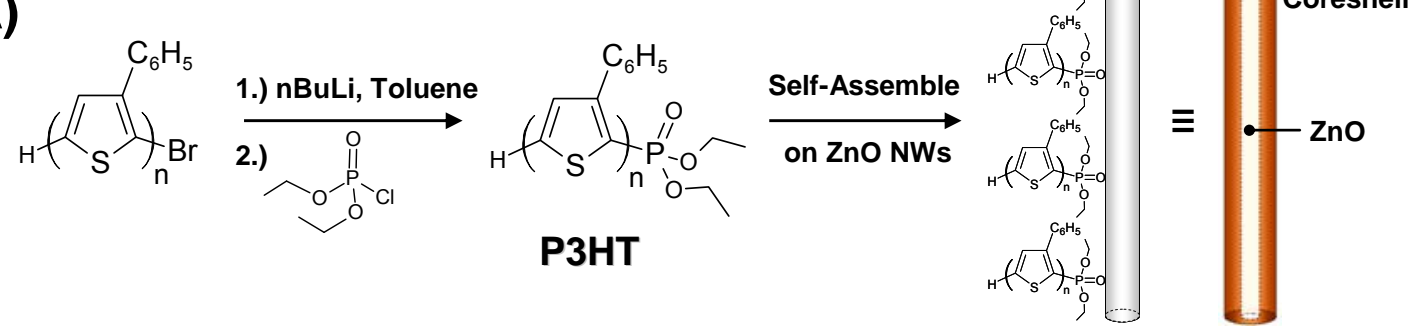

B)

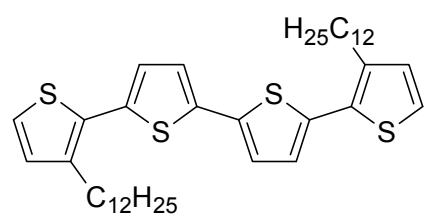

1.) $\mathrm{nBuLi},-78^{\circ} \mathrm{C}$

2.)<smiles>CCOP(=O)(Cl)OCC</smiles>

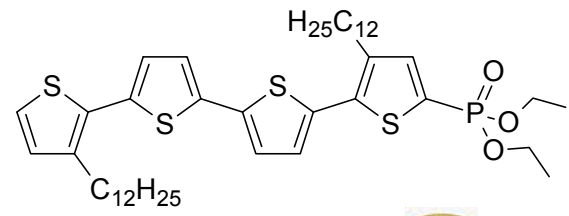

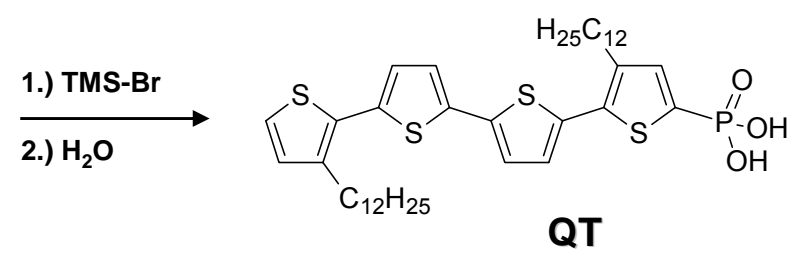

$\stackrel{\text { Self-Assemble }}{\longrightarrow}$ on ZnO NWs

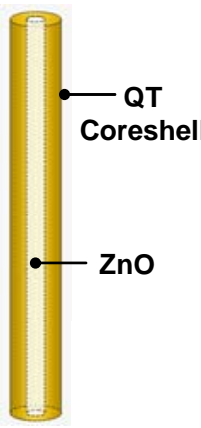

Figure 1. Synthetic pathway for end-functionalizing (A) poly(3-hexylthiophene) (P3HT) and (B) didodecylquaterthiophene (QT) with a phosphonic ester and acid, respectively. The oligothiophenes are self-assembled onto $\mathrm{ZnO}$ nanowires overnight in $2 \mathrm{mM}$ chlorobenzene solutions. 


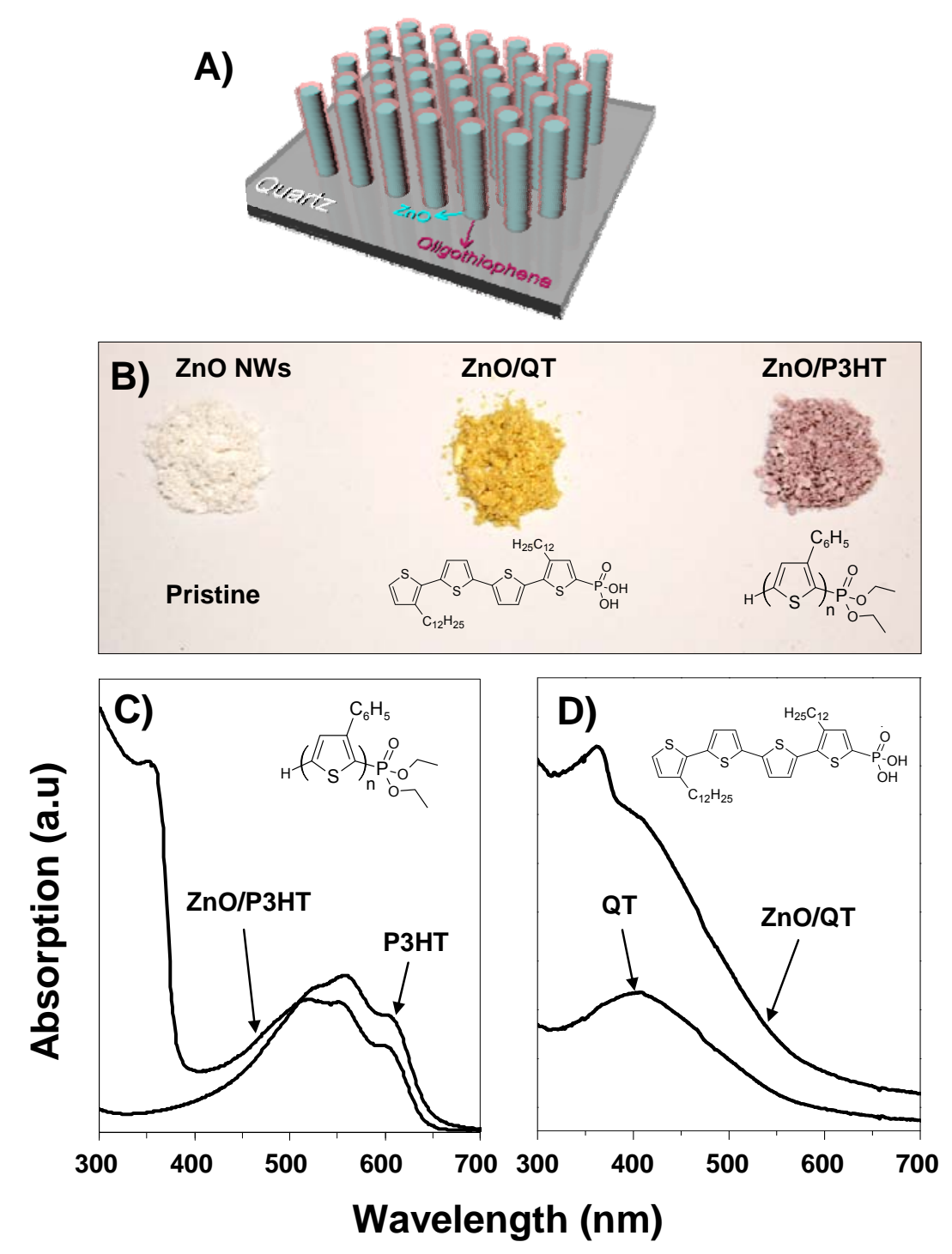

Figure 2. (A) Schematic structure of the oligothiophene-modified $\mathrm{ZnO}$ nanowire substrate utilized for UV-vis absorption measurements. (B) Digital photograph of the asprepared solution-phase $\mathrm{ZnO}$ nanowires, $\mathrm{ZnO} / \mathrm{QT}$, and $\mathrm{ZnO} / \mathrm{P} 3 \mathrm{HT}$ in their dry powder form. (C) A UV-vis absorption spectra of the P3HT-modified ZnO nanowires, and (D) QT-modified $\mathrm{ZnO}$ nanowires. An overlay of the pristine polymer and oligomer is also included in the respective spectra. 

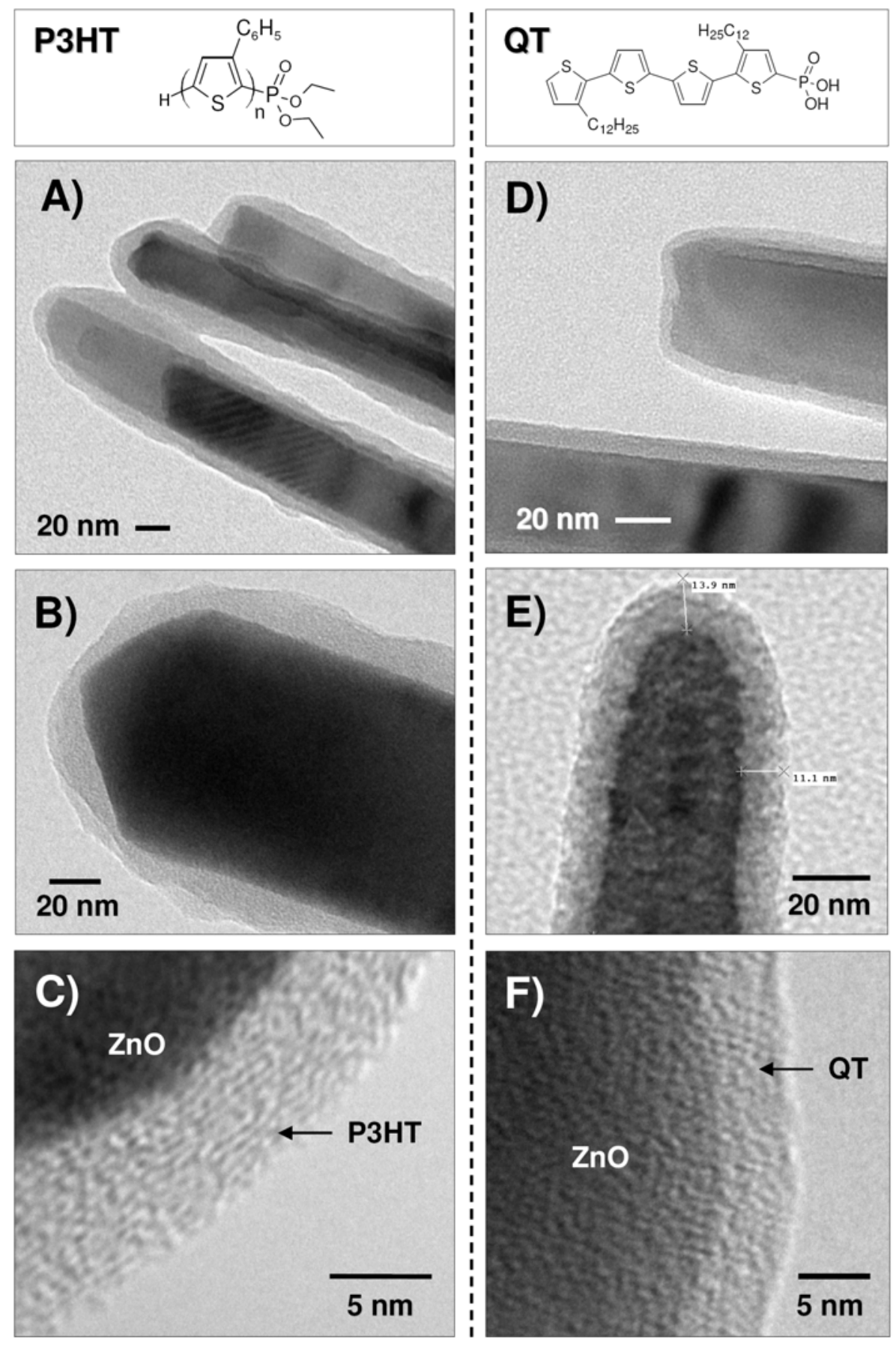

Figure 3. Transmission electron microscopy (TEM) images of (A-C) ZnO/P3HT coreshell nanowires, and (D-F) $\mathrm{ZnO} / \mathrm{QT}$ core-shell nanowires. 

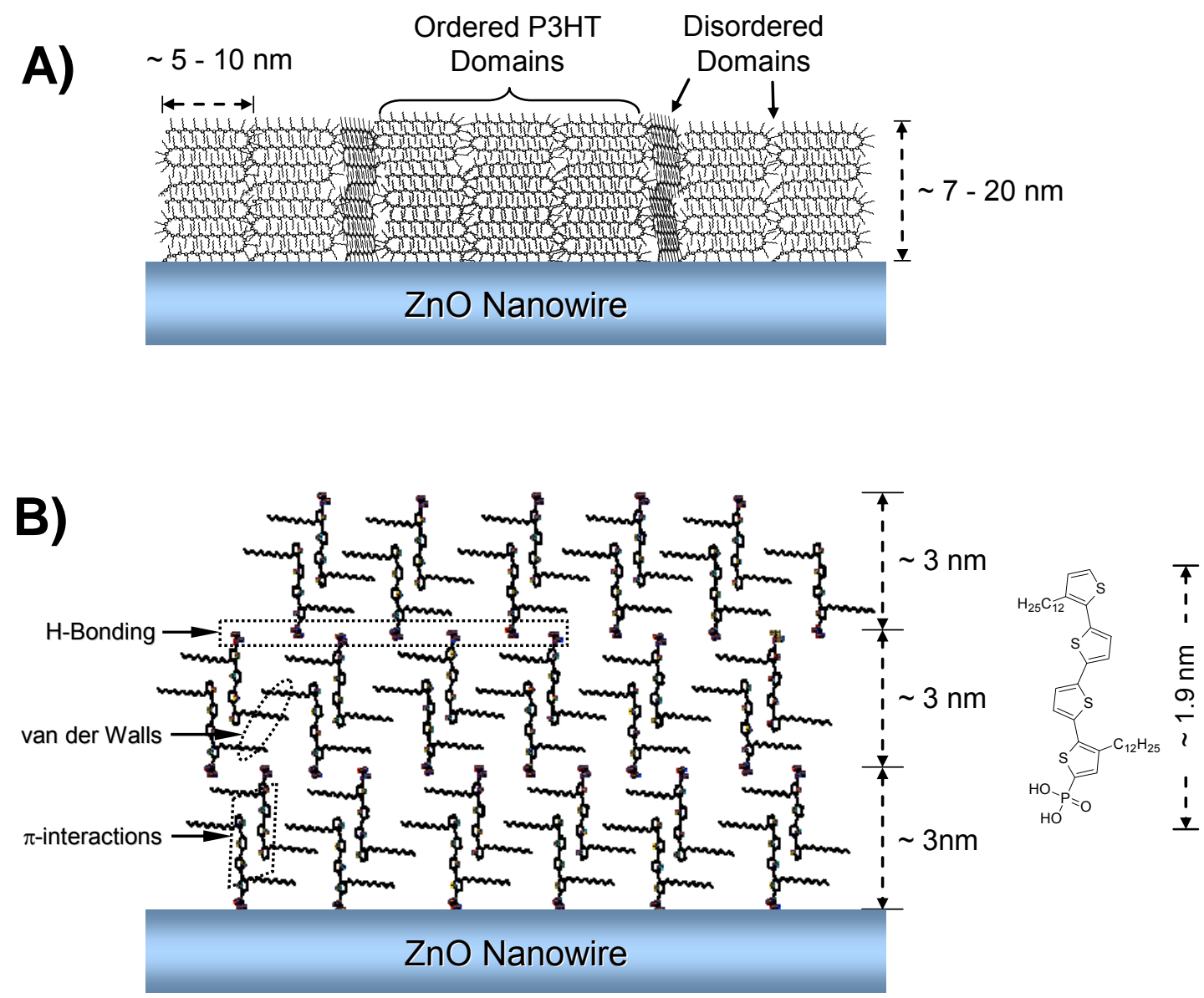

Figure 4. (A) Diagrammatic representation of the $\mathrm{ZnO} / \mathrm{P} 3 \mathrm{HT}$ interface. The illustration is not to scale and is intended to estimate the lamellar organization of P3HT on ZnO. The self-assembled polymer thin film is believed to contain ordered domains and regions of azimuthal disorder. (B) Speculated molecular packing at the $\mathrm{ZnO} / \mathrm{QT}$ nanowire interface. Also shown are the three molecular forces that assist in interfacial self-assembly. 

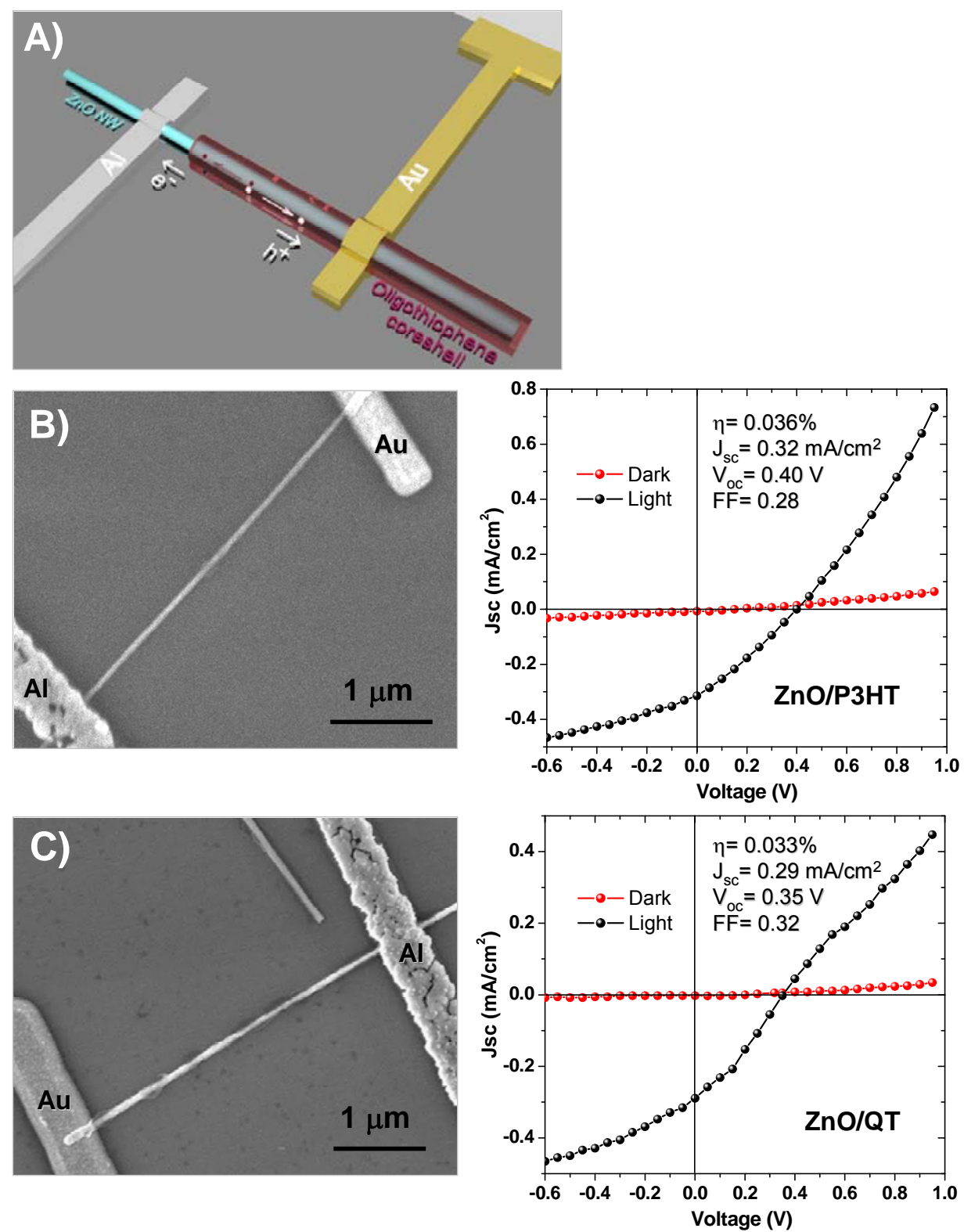

Figure 5. (A) Schematic configuration of a discrete $\mathrm{ZnO}$ /Oligothiophene nanowire solar cell. (B) SEM image of a discrete $\mathrm{ZnO} / \mathrm{P} 3 \mathrm{HTPO}$ nanowire device fabricated by EBL and the corresponding current-voltage characteristics. (C) SEM image of a discrete $\mathrm{ZnO} / \mathrm{QTPO}$ nanowire device and the current-voltage characteristics. The devices were measured under AM 1.5 irradiation $\left(100 \mathrm{~mW} / \mathrm{cm}^{2}\right)$. 


\title{
Supporting Information
}

\section{Oligo- and Poly-thiophene/ZnO Hybrid Nanowire Solar Cells}

\author{
Alejandro L. Briseno, Thomas W. Holcombe, Akram I. Boukai, Erik C. Garnett, Steve \\ W. Shelton, Jean J. M. Fréchet*, Peidong Yang* \\ Department of Chemistry, University of California, Berkeley, California 94720, and \\ Materials Sciences Division, Lawrence Berkeley National Laboratory, Berkeley, \\ California 94720
}

\section{Experimental}

Structural Characterization. Scanning electron microscopy was done on a JEOL JSM$6340 \mathrm{~F}$ operating at $5 \mathrm{kV}$. Transmission electron microscopy was performed on a Philips CM200 FEG operating at $200 \mathrm{kV}$.

End-Functionalization of P3HT. In a $100 \mathrm{~mL}$ 3-neck round-bottom flask, $41 \mathrm{mg}$ of P3HT was dissolved in $50 \mathrm{~mL}$ of anhydrous toluene. This required heating at $90{ }^{\circ} \mathrm{C}$ for 2 hours. The solution was then cooled to room-temperature and then further cooled to $0{ }^{\circ} \mathrm{C}$. The bright orange solution turns dark orange and opaque at this point. $0.2 \mathrm{~mL}$ of $2.5 \mathrm{M} \mathrm{nBuLi}$ was then added dropwise and stirred at $0{ }^{\circ} \mathrm{C}$ for 5 minutes and at room temperature for 1 hour before the reaction was cooled back down to $0{ }^{\circ} \mathrm{C}$ and $0.3 \mathrm{~mL}$ of diethylchlorophosphate was added dropwise. After 2 hours, the reaction was precipitated into methanol $(200 \mathrm{~mL})$ and filtered, with extensive methanol and acetone washing.

QT-ester. In a $100 \mathrm{~mL}$ 3-neck round bottom flask, 5,5'-bis(3-dodecyl-2-thienyl)-2,2'bithiophene (Aldrich, $0.50 \mathrm{~g}, 0.749 \mathrm{mmol}$ ) was dissolved in $40 \mathrm{~mL}$ of anhydrous THF. The reaction was cooled to $-78{ }^{\circ} \mathrm{C}$ (solution became a slurry) and n-butyllithium (Aldrich, $0.315 \mathrm{~mL} 2.5 \mathrm{M}$ in hexanes, $1.15 \mathrm{eq}$ ) was added dropwise. The reaction was stirred at at $-78{ }^{\circ} \mathrm{C}$ for 2.5 hours and then diethylchlorophosphate was added dropwise (Aldrich, $0.155 \mathrm{~g}, 0.898 \mathrm{mmol}, 1.2 \mathrm{eq}$ ). The reaction becomes an orange color at $-78{ }^{\circ} \mathrm{C}$ and then turns red over the course of 6 hours as the reactions warms to room-temperature. The crude reaction was quenched with a few drops of water and then diluted with diethylether and washed with $1 \mathrm{M} \mathrm{HCl}$. The ether was evaporated to yield crude product that was purified by column chromatography (40\% EtOAc in Hexanes). $130 \mathrm{mg}, 22 \%$ yield. 1H NMR (400 MHz, Acetone- $\mathrm{d}_{6} \delta \mathrm{ppm} 7.49(\mathrm{~d}, \mathrm{~J}=8.53 \mathrm{~Hz}, 1 \mathrm{H}), 7.38(\mathrm{~d}, \mathrm{~J}=5.21$ $\mathrm{Hz}, 1 \mathrm{H}), 7.32(\mathrm{dd}, \mathrm{J}=3.77,1.46 \mathrm{~Hz}, 2 \mathrm{H}), 7.25(\mathrm{~d}, \mathrm{~J}=3.83 \mathrm{~Hz}, 1 \mathrm{H}), 7.12(\mathrm{~d}, \mathrm{~J}=3.80 \mathrm{~Hz}$, $1 \mathrm{H}), 7.03(\mathrm{~d}, \mathrm{~J}=5.21 \mathrm{~Hz}, 1 \mathrm{H}), 4.15-4.06(\mathrm{~m}, 4 \mathrm{H}), 2.86-2.78(\mathrm{~m}, 6 \mathrm{H}), 1.71-1.61(\mathrm{~m}, 4 \mathrm{H})$, $1.40-1.15(\mathrm{~m}, 44 \mathrm{H}), 0.84(\mathrm{t}, \mathrm{J}=6.76,6.76 \mathrm{~Hz}, 6 \mathrm{H}) 31 \mathrm{P}(9.86)$

End Functionalization of QT-Acid. In a 1-neck $25 \mathrm{~mL}$ round-bottom flask $130 \mathrm{mg}$ of DD-QTPO-Ester was dissolved in $7 \mathrm{~mL}$ of dichloromethane. $0.2 \mathrm{~mL}$ of bromotrimethylsilane ( 8 eqs) and $0.21 \mathrm{~mL}$ of triethylamine ( 8 eqs) were stirred overnight. $1 \mathrm{~mL}$ of water was added and stirred for an hour as an emulsion with dichloromethane. $\sim 50 \mathrm{~mL}$ of dichloromethane was added and the organic phase washed with $1 \mathrm{M} \mathrm{HCl}$. The 
dichloromethane was removed under reduced pressure to yield a yellow solid (90 $\mathrm{mg}$, $75 \%$ yield). $1 \mathrm{H}$ NMR (400 MHz, $\mathrm{CD}_{2} \mathrm{Cl}_{2} \delta \mathrm{ppm}$ 7.70-7.30 (m, 2H), 7.21-6.81 (m, 7H), 2.78-2.65 (m, 4H), 1.69-1.52 (m, 4H), 1.38-1.13 (m, 38H), 0.88-0.76 (m, 6H). 
Acknowledgements: This work was supported by the Director, Office of Science, Office of Basic Energy Sciences, Material Sciences and Engineering Division, of the U.S. Department of Energy under Contract No. DE-AC02-05CH11231. We thank the National Center for Electron Microscopy for the use of their facilities. 